\title{
ECONOMIC GROWTH FACTORS IN 2010- THE FIRST HALF OF 2011
}

\author{
E.Astafieva
}

The results of decomposition of output growth rates demonstrate that in the period of 2012 - the first half year of 2013 the rate of GDP growth was predominantly influenced by the inputs provided by the main production factors. Labor and capital inputs, on the average, determine $80 \%$ of the rate of GDP growth; in other words, at present the Russian economy's growth is achieved in the main due to the effect of extensive factors. At the same time, labor and capital inputs display a declining growth rate.

It has become a widespread international practice, when analyzing the prospects of economic development, to apply methods based on by-factor decomposition of economic growth. Decomposition means that the rate of output growth is broken into extensive and intensive components depending on the specific values of differential production function. Labor and capital inputs are considered to be extensive factors whose value is derived by multiplying the values of both factors (the actual number of the employed and the volume of fixed assets) by the intensity of their use (the working hours of one employed person and the load on production capacities). Intensive growth components are represented by the residual that cannot be explained by the effect of the main factors and is called combined factor productivity (CFP). The results of decomposition reflect transformations in the structure of economic growth, thus making it possible to single out the most relevant factors determining changes in the dynamics of the rate of output growth.

According to data published by Rosstat, the period of 2012 through the first half year of 2013 demonstrated a positive quarterly rate of GDP growth amounting on the average to $2.9 \%$. At the same time, in the first half year of 2013 the rate of output growth was found to be significantly below its level recorded in 2012 (1.8\% against 3.5\%). On the average over the period under consideration, the decline of the quarterly growth rate of GDP amounted to 0.6 p.p. (when fitted to a linear trend -0.7 p.p. ${ }^{1}$ )

In 2012 and the first half year of 2013, changes in the GDP volume displayed the same direction as those in the inputs contributed by the main factors: output growth was followed by growth of the main extensive factors. In 2012, changes in labor and capital inputs on the average determined $93 \%$ of the rate of GDP growth; in the first half year of $2013-59 \%$.

1 A linear trend is fitted to the rate of growth in order to make the resulting estimates less dependent on the choice of first and last estimation periods.
As shown by factor decomposition (Table 1, Fig. 1) over the period under consideration, 11\% of GDP growth can be explained by changes in labor input. In 2012 , the input provided by that component was responsible on the average for $13 \%$ of the rate of output growth, and in the first half year of 2013 its input was on the average negative, which was determined by the declining labor inputs in Q2 2013. The input provided by changes in the volume of used production capital to the rate of GDP growth was on the average $71 \%$. Similarly to labor input, capital input in the rate of GDP growth displayed a downward trend over the first half year of 2013, being on the average responsible during that period for $64 \%$ of GDP growth. At the same time, over the entire period under consideration (with the exception of Q1 2013), capital input acted as the most relevant economic growth factor, thus determining a major part of the rate of GDP growth. In 2012 and the first half year of 2013, CFP was determining on the average $18 \%$ the rate of GDP growth.

Labor input demonstrated a downward growth rate, which on the average, over that period, amounted to 0.4 p.p. The decline in the growth rate of labor input was determined by the downward movement of both its components; moreover, the growth rates of both the number of employed and their working hours towards the period's end shift onto the negative side. The quarterly structure of labor input over the period under consideration is rather heterogeneous. The intensity of the use of labor reserves was displaying stronger fluctuations of its input in the rate of growth: the number of working hours was on the decline in Q3 2012 and the first two quarters of 2013, and so the input of that component in the growth rate of GDP over those periods was negative. The average quarterly decline of the growth rate of employment intensity was 0.2 p.p. The drop of the growth rate of labor reserves also amounted to 0.2 p.p., but in contrast to the other component the growth rate of employment was negative only in Q2 2013. It should be noted that, for the first time over the entire post-crisis period, labor reserves began to shrink. 
STRUCTURE OF GDP GROWTH RATE (AGAINST SAME PERIOD OF PREVIOUS YEAR)

\begin{tabular}{|l|c|c|c|c|c|c|c|}
\hline \multicolumn{5}{|c|}{} & Q1 2012 & Q2 2012 & \multicolumn{2}{|c|}{ Q3 2012 } & Q4 2012 & Q1 2013 & Q2 2013 \\
\hline GDP & 4.75 & 4.26 & 3.00 & 2.10 & 1.59 & $1.90^{*}$ \\
\hline I. Factor inputs & 4.86 & 3.54 & 1.42 & 2.96 & 0.81 & 1.25 \\
\hline I.1 Labor & 1.49 & 1.10 & -0.65 & 0.81 & 0.16 & -0.40 \\
\hline Employment & 0.44 & 0.75 & 0.31 & 0.35 & 0.66 & -0.34 \\
\hline Working hours & 1.05 & 0.35 & -0.96 & 0.46 & -0.50 & $-0.05^{* *}$ \\
\hline I.2 Capital & 3.37 & 2.44 & 2.08 & 2.15 & 0.65 & 1.65 \\
\hline Fixed assets & 1.74 & 1.79 & 1.85 & 1.69 & 1.41 & 1.47 \\
\hline Capacity load & 1.63 & 0.66 & 0.22 & 0.46 & -0.76 & 0.18 \\
\hline II. CFP & -0.10 & 0.72 & 1.58 & -0.86 & 0.78 & 0.65 \\
\hline & & as $\%$ of GDP growth rate & & & \\
\hline GDP & 100.0 & 100.0 & 100.0 & 100.0 & 100.0 & 100.0 \\
\hline I. Factor inputs & 102.2 & 83.2 & 47.3 & 140.7 & 51.1 & 66.0 \\
\hline I.1 Labor & 31.3 & 25.8 & -21.7 & 38.3 & 9.9 & -20.8 \\
\hline Employment & 9.2 & 17.7 & 10.4 & 16.4 & 41.3 & -18.1 \\
\hline Working hours & 22.1 & 8.1 & -32.1 & 21.9 & -31.4 & -2.7 \\
\hline I.2 Capital & 70.9 & 57.4 & 69.1 & 102.4 & 41.2 & 86.8 \\
\hline Fixed assets & 36.6 & 42.0 & 61.7 & 80.6 & 88.7 & 77.5 \\
\hline Capacity load & 34.3 & 15.4 & 7.4 & 21.9 & -47.6 & 9.3 \\
\hline II. CFP & -2.2 & 16.8 & 52.7 & -40.7 & 48.9 & 34.0 \\
\hline
\end{tabular}

* the RF Ministry of Economic Development's estimates

** the values of working hours for Q2 2011 are based on an autoregressive - moving-average model, calculated by applying data submitted over the period from Q1 1999 through Q1 2013.

Similarly to labor inputs, capital inputs demonstrated a declining growth rate, its average quarterly drop amounting to 0.3 p.p. Nevertheless, capital input remains the most important factor whose predominant role in the growth rate of GDP was evident over the entire period under consideration (except in Q1 2013). In accordance with the applied assessment methodology, ${ }^{1}$ the dynamics of capital reserves was determined by changes in the volume of investments in fixed assets, whose growth rate was increasing on the average 3.6 p.p. every quarter (from 16.5\% in Q1 2012 to $-1.7 \%$ in Q2 2013). It should be noted that, in the first half-year periods of 2012 and 2013, the volume of investments in fixed assets in real terms remained below its level in 2008. As a result, in conditions of the existing degree of wear and tear of fixed assets, the growth rate of capital reserves remains practically unchanged, demonstrating only a negligible decline. On the average, in 2012 and the first half year of 2013, the growth rate of fixed assets was responsible for $64 \%$ of the rate of GDP growth, while the fluctuations in their load - for $7 \%$. However, the

1 In the absence of quarterly statistics, growth of the main factors is assessed on the basis of the assumption that the coefficient of retirement of fixed assets and the share of investments earmarked for their renewal are constant values. It should be noted that the estimates thus obtained may be biased because they are not adjusted by the time lag between the receipt of investments and the moment of their use. structure of capital input is characterized by redistribution, by relevance, of its components' inputs, so over the entire period changes in capital reserves reveal their more substantial input in the rate of GDP growth by comparison with the input determined by fluctuations in their load. The mean quarterly decline in the growth rate of the intensity of use of fixed assets was 0.3 p.p., and the decline of the volume of fixed assets -0.1 p.p.

Over the period under consideration, the impact of combined factor productivity (CFP) on output growth was distributed unevenly between different quarters: thus, in Q1 and Q2 2012 the average input of that component in GDP growth rate was 35\%; in Q1 and Q4 it was negative; and the first half year of 2013, SFP determined on the average $42 \%$ of the rate of output growth. Thus, the growth rate SFP displayed an upward trend: the average quarterly increase in the productivity growth rate was 0.2 p.p. (when fitted to a linear trend -0.1 p.p.).

The observed influence of CFP on the movement of output by no means reflects only the impact of productivity factors determined by technological changes. It also incorporates some components not included in the estimates of the main factors, as well as biases caused by the specific assessment methodology, in particular those determined by an uneven movement of the value indices applied in the decomposition (out- 
put and capital) ${ }^{1}$. As shown by the estimates obtained for earlier periods, these biases are significant in conditions of Russia's economic system, which is strongly influenced by changes in prices on international raw materials markets, especially in a short-term perspective.

In accordance with the obtained results ${ }^{2}$, from Q2 2012 onwards, the input of changes in oil prices in the rate of GDP growth began to be negative. On the average, during the period under consideration, changes in the price factor were conducive to a slowdown of the growth rate of GDP, while technological productivity ('final residual') was determining approximately $48 \%$ of the rate of output growth. Changes in the growth rate of the 'technological' component obtained as a

1 The 'value' estimate of productivity becomes similar to its physical estimate in a situation of long-term balance in the economy and perfect competition. In other words, this similarity can be possible only when a system's current balance incorporates all the potential exogenous shocks.

2 The singling out, in CFP's structure, of a 'situational' component and further decomposition of the rate of output growth is based on the existence of a statistically significant correlation between the growth rates CFP and world oil prices, which is estimated by applying a regression model based on annual data for the period 1993-2012. The resulting 'final residual', cleared of the effects produced by fluctuations of prices on world raw materials markets, represents a more correct index of technological productivity, i. e., the intensive component of output growth.

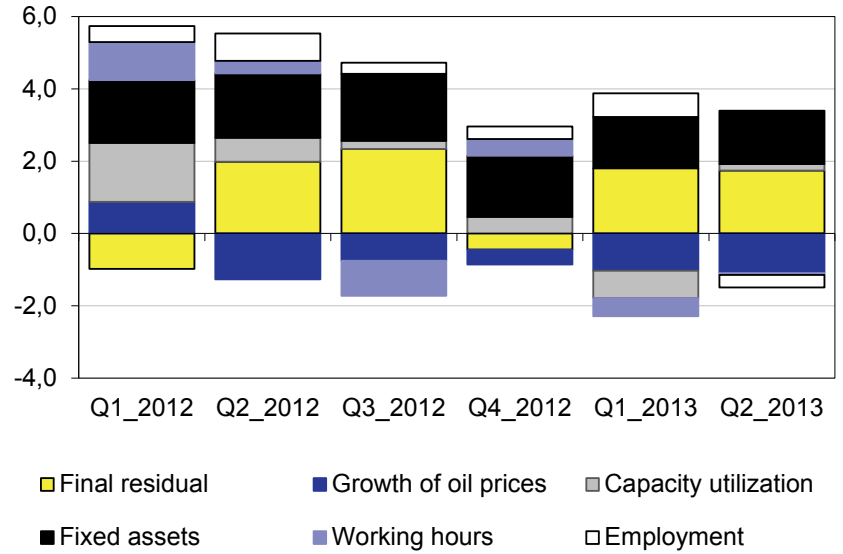

Fig. 1. By-factor Decomposition of GDP Growth (Agains Same Periods of Previous Year), with Estimates of Input Provided by Oil Prices.

result of singling out, as a separate factor, the situation on world raw materials markets, differ little from the movement pattern displayed by SFP. The growth rate of 'final residual' was negative in Q1 and Q4 2012. However, on the whole over the period under consideration, the movement of the 'technological' component demonstrated an increasing growth rate - on the average by 0.5 p.p. per quarter (when fitted to a linear trend - by 0.3 p.p.). 